 \\ A VIBGYOR Metallurgy and Metal Physics
}

\section{Laser Treatment of Soft Magnetic Materials - Effect and Properties}

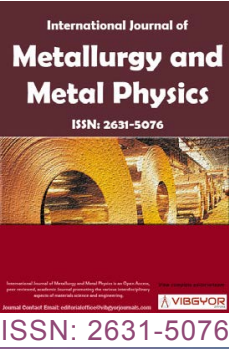

\section{P Delarbre*}

Department of R\&D, PMG Fussen GmbH, Germany

\begin{abstract}
The mechanical strength of Somaloy ${ }^{\circledR} 5 \mathrm{P}$ is with a value of $50-60 \mathrm{MPa}$ after the heat treatment at temperature $550-650{ }^{\circ} \mathrm{C}$ under a protective atmosphere for magnetic applications. The strength of sintering iron alloys is $>300 \mathrm{MPa}$ and can obtain $900 \mathrm{MPa}$ for high performance iron alloys like PM materials Fe-NIMoCuC or FE-CrMoC. For this reason the technology of selective laser " sintering " without the addition of a foreign powder was experimented to evaluate the influence of this technology on the materialographical structure and on the mechanical and magnetic properties of the Somaloy ${ }^{\circledR}$ 5P. The goal is to obtain a densification layer with a high density - poor porosity - in the area of the surface without to change the pore distribution and the structure in the core.

This paper investigates the effect of a selective laser " sintering " on the surface of a soft magnetic component and describes the final properties of component after the treatment. Finally, a proposal of an optimised process recommendation for the selective laser sintering of Somaloy ${ }^{\circledR}$ P components is made.
\end{abstract}

\section{Keywords}

Powder metallurgy, Soft magnetic materials, Magnetic properties

\section{Introduction}

The PM material Somaloy ${ }^{\circledR}$ [1-5] of the company Höganäs which is the considered Trademark for soft magnetic composite powders, was used for the experimental procedure for selective laser sintering. Somaloy ${ }^{\circledR}$ are pure iron, water atomized powder with an electrically insulating coating (Figure 1 ).

The insulating coating is one of the key factors to balance of good permeability, low core loss and good mechanical strength. The density of this material after the compacting under axial conditions is in the range between 7.2 and $7.4 \mathrm{~g} / \mathrm{cm}^{3}$. The material with the density consists of material and pores and for this reason is not comparable to a conventional steel (for example C15) that has the maximum density of $7.8 \mathrm{~g} / \mathrm{cm}^{3}$. The following micrographs (Figure 2) show the difference between a steel and a PM steel with the presence of pores due to the density $<7.8 \mathrm{~g} / \mathrm{cm}^{3}$.

Selective laser sintering (SLS) is a manufacturing technique that uses a laser for example carbon dioxide laser as the power laser to sinter powdered material [6] aiming the laser automatically at points

*Corresponding author: P Delarbre, Dr.-Ing, Department of R\&D, PMG Fussen GmbH, Germany

Accepted: October 19, 2019; Published: October 21, 2019

Copyright: (c) 2019 Delarbre P. This is an open-access article distributed under the terms of the Creative Commons Attribution License, which permits unrestricted use, distribution, and reproduction in any medium, provided the original author and source are credited.

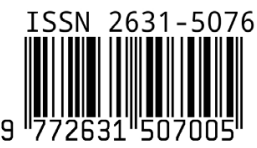

Delarbre. Int J Metall Met Phys 2019, 4:041 


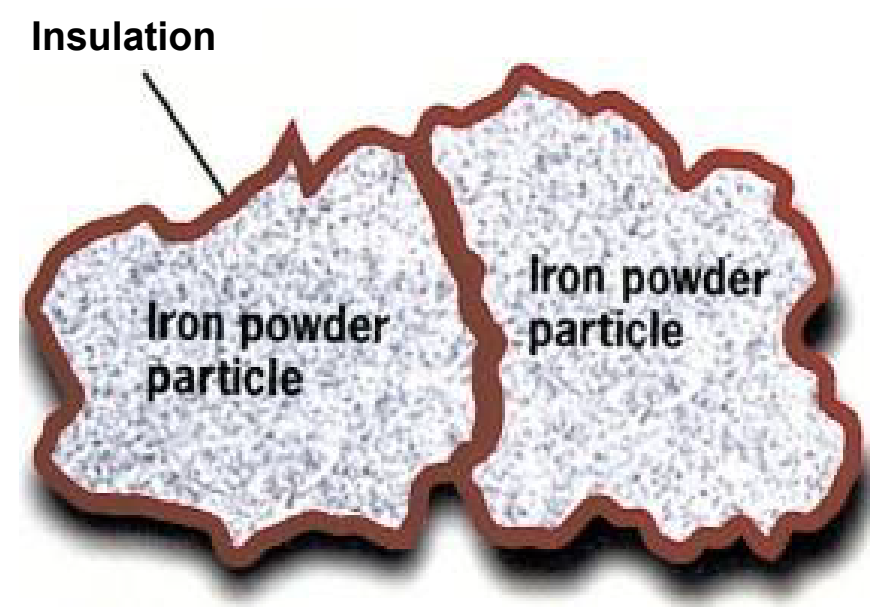

Figure 1: SMC powder particles covered with an insulating film [1].
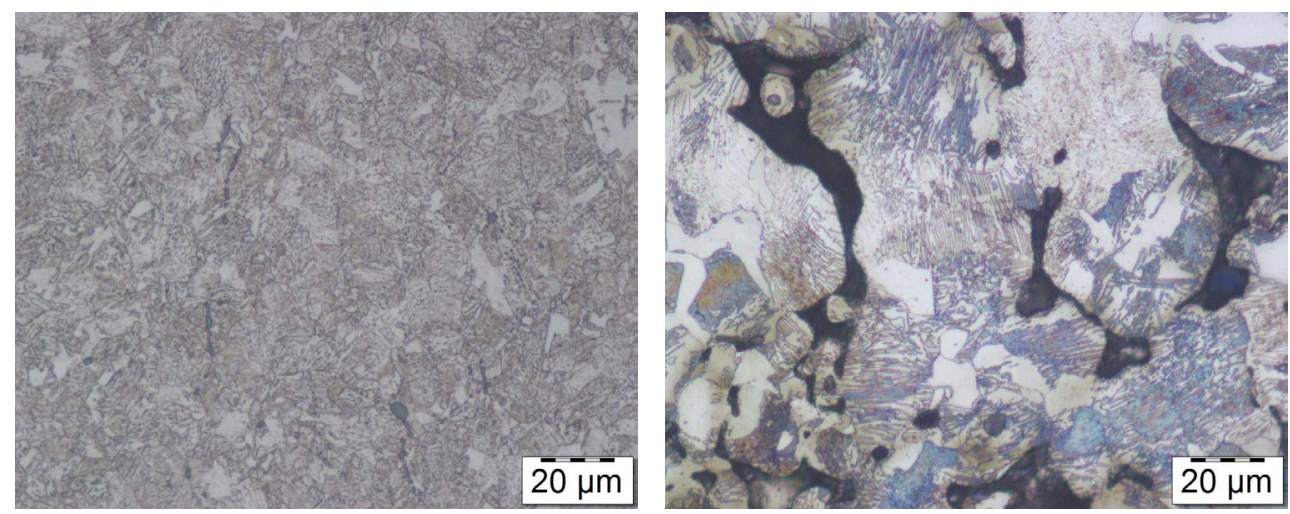

Figure 2: Microstructure of a steel with martensite and a PM steel with ferrite, pearlite and pores (black areas).

in space binding the material together to create a solid structure without the presence of pores. In single component powder, the laser melts only the outer surface of the particles (surface melting) fusing the solid no melting cores.

\section{Experimental Procedure}

The PM material Somaloy 5P Höganäs was used for the experimental procedure for selective laser sintering. The powder for the manufacturing of the toroid is a press-ready mix with particle size of about $250 \mu \mathrm{m}$. With ultra-high insulation suitable for higher permeability and low loss applications.

Toroids with an inner diameter of $45 \mathrm{~mm}$, an outer diameter of $55 \mathrm{~mm}$ and a height of $5 \mathrm{~mm}$ were compacted under a high compaction pressure with a die temperature of about $80{ }^{\circ} \mathrm{C}$ to obtain a density of $7.2 \mathrm{~g} / \mathrm{cm}^{3}$. The toroids were heat treated at $650{ }^{\circ} \mathrm{C}$ under pure nitrogen in a belt furnace. Heat treatment temperature, heat treatment time were chosen to avoid the de- terioration of the insulating layer. The coating will start to deteriorate at higher temperatures due to thermally activated diffusion processes, leading to decrease component resistivity. For this soft magnetic materials, the heat treatment temperature is lower that the conventionally sintering temperature for the iron or iron-alloys like $\mathrm{Fe}-\mathrm{CrMo}, \mathrm{Fe}-\mathrm{NiMoCu}$ that is normally at $1120{ }^{\circ} \mathrm{C}$ or $>1120^{\circ} \mathrm{C}$ under a protective atmosphere of a mixture of nitrogen-hydrogen.

Somaloy ${ }^{\circledR} 5$ P with a density of $7.2 \mathrm{~g} / \mathrm{cm}^{3}$ should be heat-treated in pure nitrogen atmosphere to avoid poor performance of the magnetic properties. The results are very logical because a component with low density - in this case $7.2 \mathrm{~g} / \mathrm{cm}^{3}$ has many open and large pores which will lead to oxygen deeply penetration inside the component. The oxidation will take place in the whole part.

The surface morphologie (Figure 3) of the heat treated toroid is free of suit and of oxide and does 


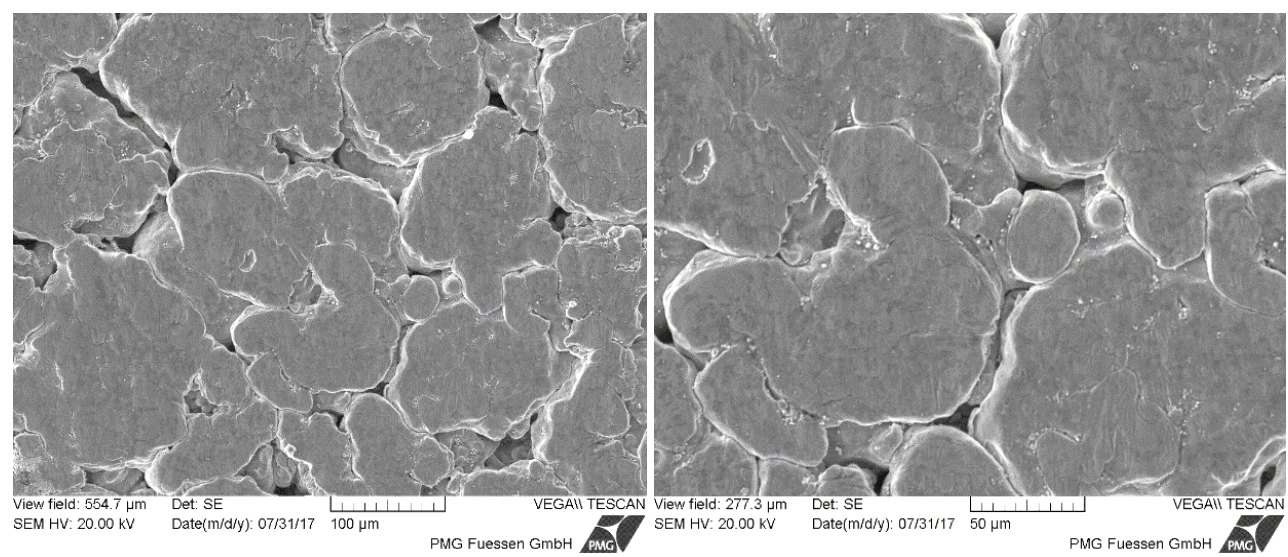

Figure 3: SEM micrographs of compacting surface after heat treatment.

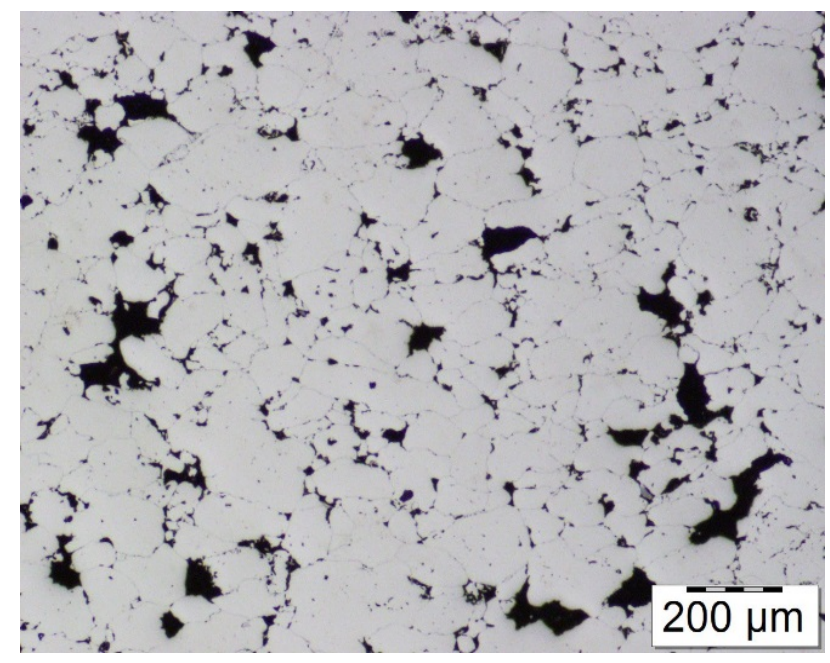

Figure 4: Microstructure of the reference toroid with a density of $7.2 \mathrm{~g} / \mathrm{cm}^{3}$.

not show a deterioration of the powder particles.

Because of the strength of the materials, the metallographical preparation of the experimental samples needs a great experience and a new method procedure. The sample were cut with a Secotom 15/50 cutting machine from the company Struers. Secotom machine performs precise and deformation-free cutting of section metals. The cooling with a special aqueous liquid permits to avoid a heating of the sample and consequently a modification of the structure. The cut piece was hot mounted $\left(180^{\circ} \mathrm{C}\right.$ at 250 bar) under an automatic process.

The next step is ground with several successively finer abrasive grits, polished until all the scratches from the last grind are removed with an automatic process for a maximum preparation quality and bests results and etched with an aqueous acid solution (3\% Nital) and then viewed on a light optic microscope at magnifications ranging from 50 to 1000 .

The microstructure in the unetched state (Figure 4) permits to observe that the lubricant is completely released from the component. The black areas are residual porosity and the white areas are the structure of the powder particles. Interparticles isolation can be seen as the grid separating particles from each other.

A scanning electron microscope (SEM) is a type of electron microscope that produces images of a sample by scanning the surface with a focused beam of electrons. The electrons interact with atoms in the sample, producing various signals that contain information about the surface topography and composition of the sample.

Under a scanning electron microscope the laser morphology surface was observed to determine the transformation of pores on the surface and compare to the reference sample in the heat treated state without the laser sintered process. If all pores at the surface are closed, the laser treatment can be considered as satisfied.

The SEM investigation (Figure 5) of the fracture surface shows that the coating layer is not deteriorated and the formation of the sintering bridges on the powder particles cannot be seen.

These metallographical observations permit to conclude that the conditions of heat treatment are satisfied for the component made of Somaloy 5P.

After the heat treatment the toroids have been selective laser sintered under a protective gas (Argon without and with addition of hy- 


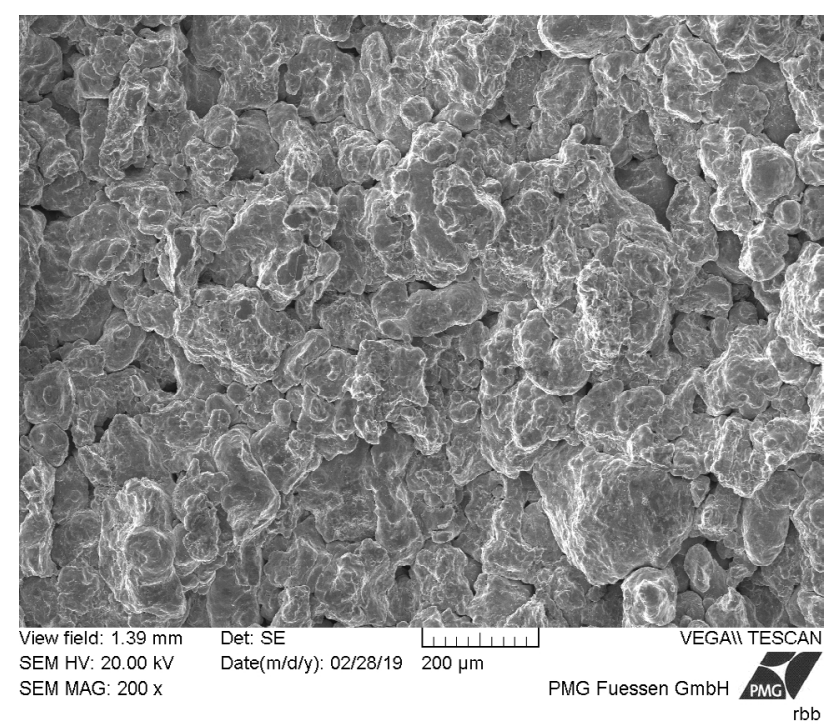

Figure 5: SEM morphologie of the reference ring.
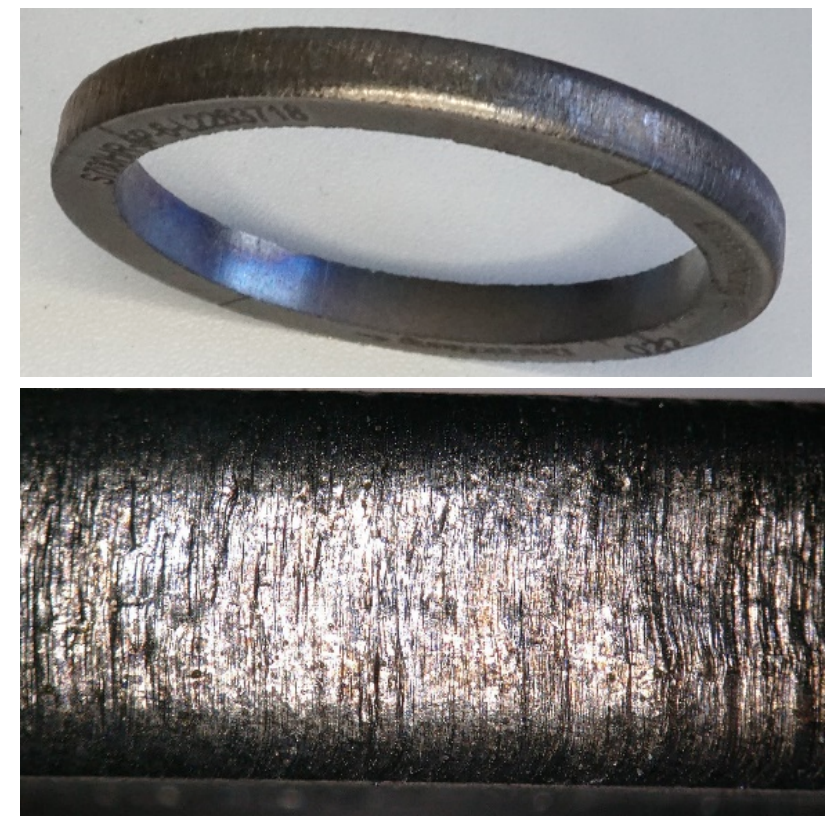

Figure 6: Macrograph of the toroid after the laser treatment.

drogen) at temperature between 900 and 1100 ${ }^{\circ} \mathrm{C}$. Scan rate, scan line speed, laser power and frequency are the variables operating parameters to obtain a densified layer of about 100-300 $\mu \mathrm{m}$ on the surface.

Three toroids have been treated by laser treatment. The goal was in the experimental procedure to realize the densification by laser process the outer diameter.

For the evaluation of the magnetic properties, the compacted and curing toroid samples have 50 drive primary and 50 sense secondary turn of win-

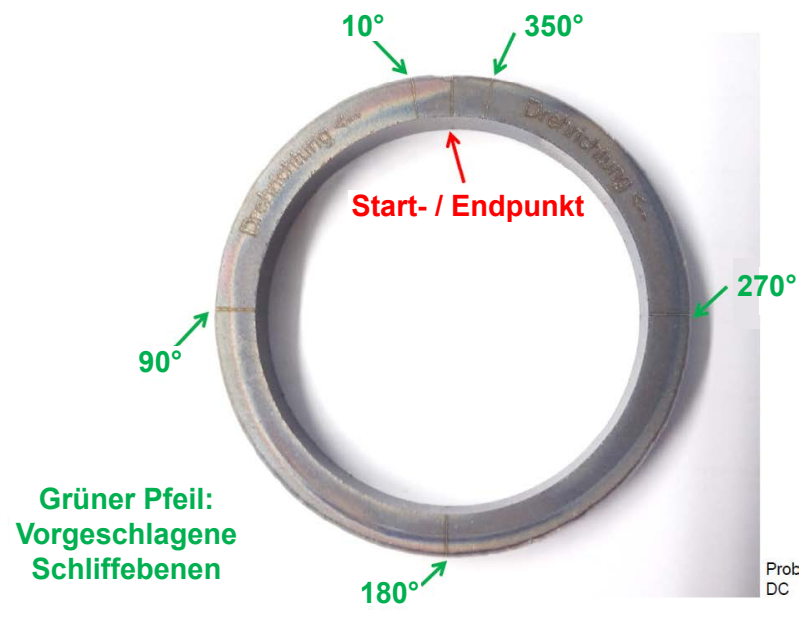

Figure 7: Localisation of the areas for the determination of the thickness.

ding.

The magnetic properties in $A C$ and $D C$ field were measured using a Brockhaus Hysteresis graph 200 MPD.

\section{Experimental Results}

\section{Macrocospical examination}

In comparison to the reference toroid without the laser treatment, the macro graphical examination of the toroids at the outer diameter (Figure 6) shows a surface that is smooth and bright. The presence of opened pores cannot be seen.

\section{Metallurgical examination}

The laser thickness has been measured at five different position as it indicates in the graphic of Figure 7 by metallurgical examination.

The thickness of the layer varied between 150 and $360 \mu \mathrm{m}$ (Figure 8). Microcracks in the layer and at the interface between the layer and the matrix cannot be detected. The porosity in the layer is reduced and free of pores $>5 \mu \mathrm{m}$. A densification in the area has taken place without to modify the core of the matrix with the presence of opened pores. The examination shows clearly that the laser treatment lead to good results.

SEM micrograph (Figure 9) shows the surface morphology between the laser treated surface without the presence of opened pores (right side) and the surface with the matrix with the presence of opened pores, that is not modified by the laser power. The transition line is free of microcracks which can appear during the cooling 
Point $10^{\circ}$

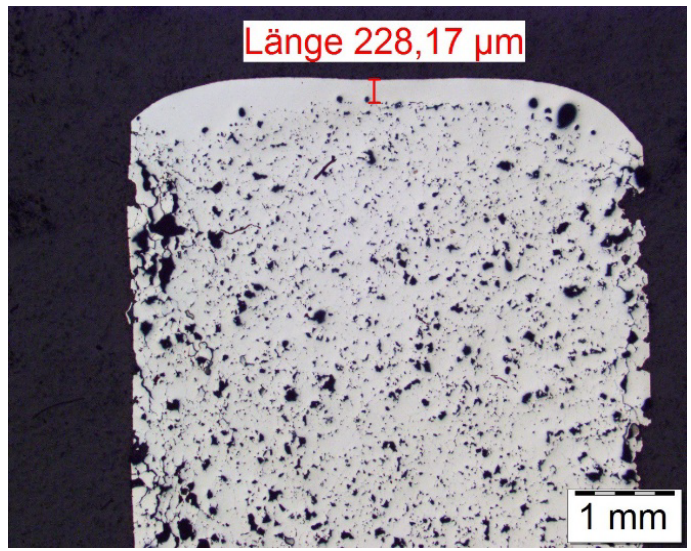

Point $180^{\circ}$

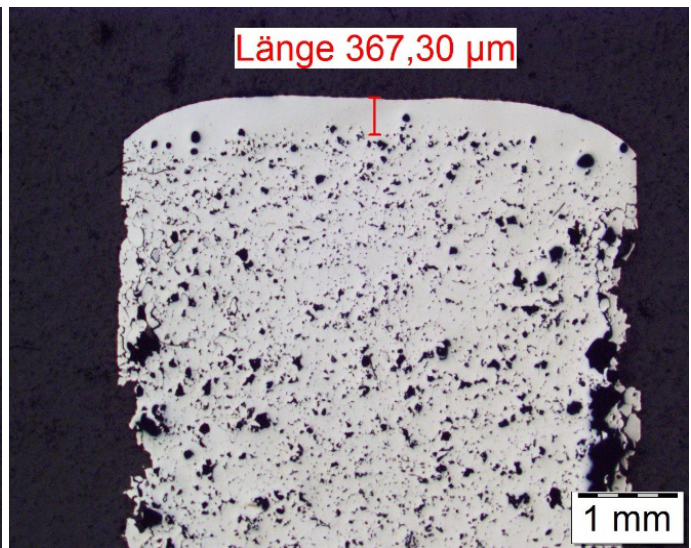

Point $270^{\circ}$

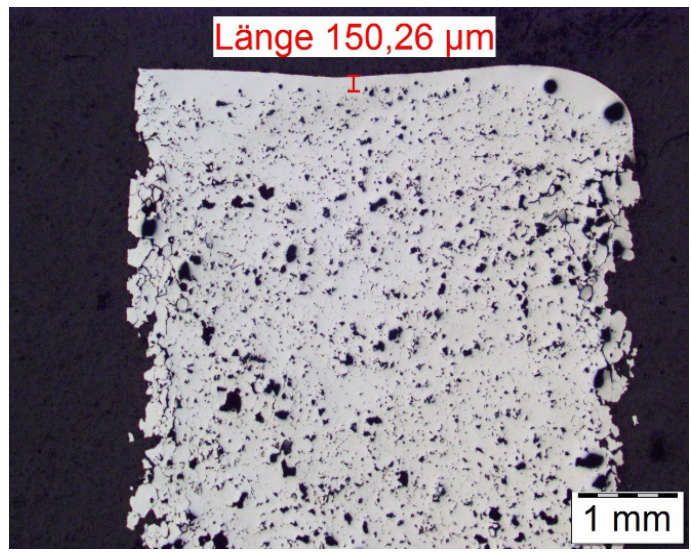

Figure 8: Micrographs of the microsections after the laser treatment at three different positions.

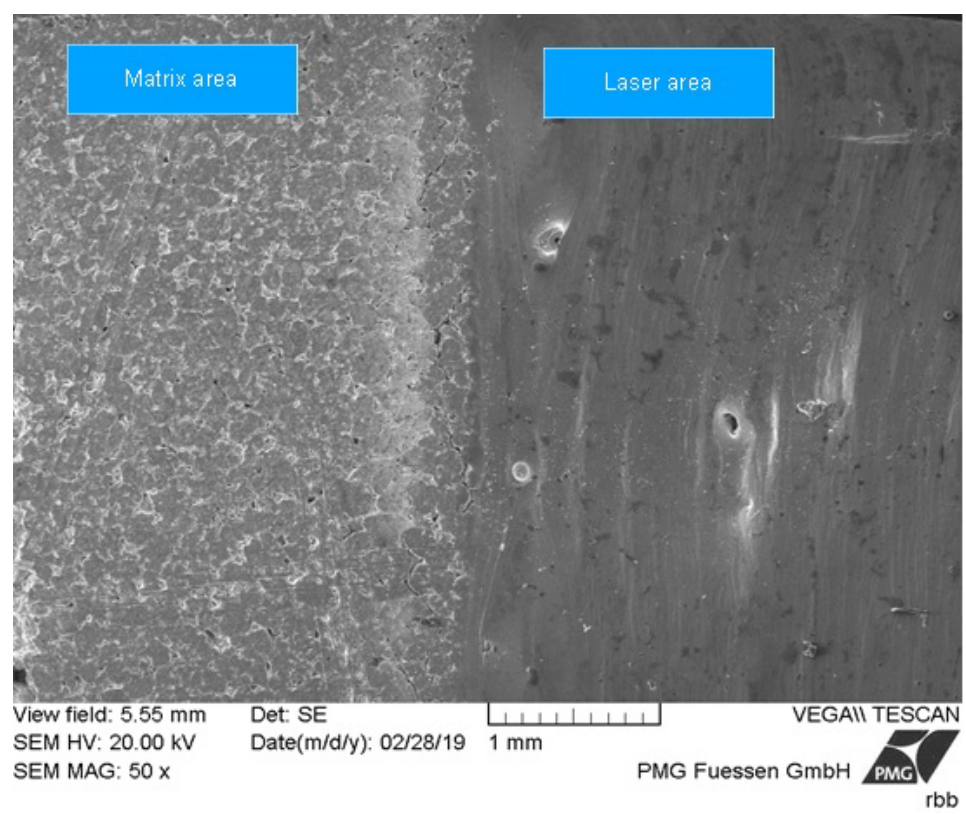

Figure 9: SEM - micrograph of the surface of the toroid after the laser treatment.

of the ring due to a stress situation.

The fracture surface of the laser treated area can be seen in the Figure 10. The structure is ductile with the formation of particles boundary without the presence of pores. It signifies that the tem- 


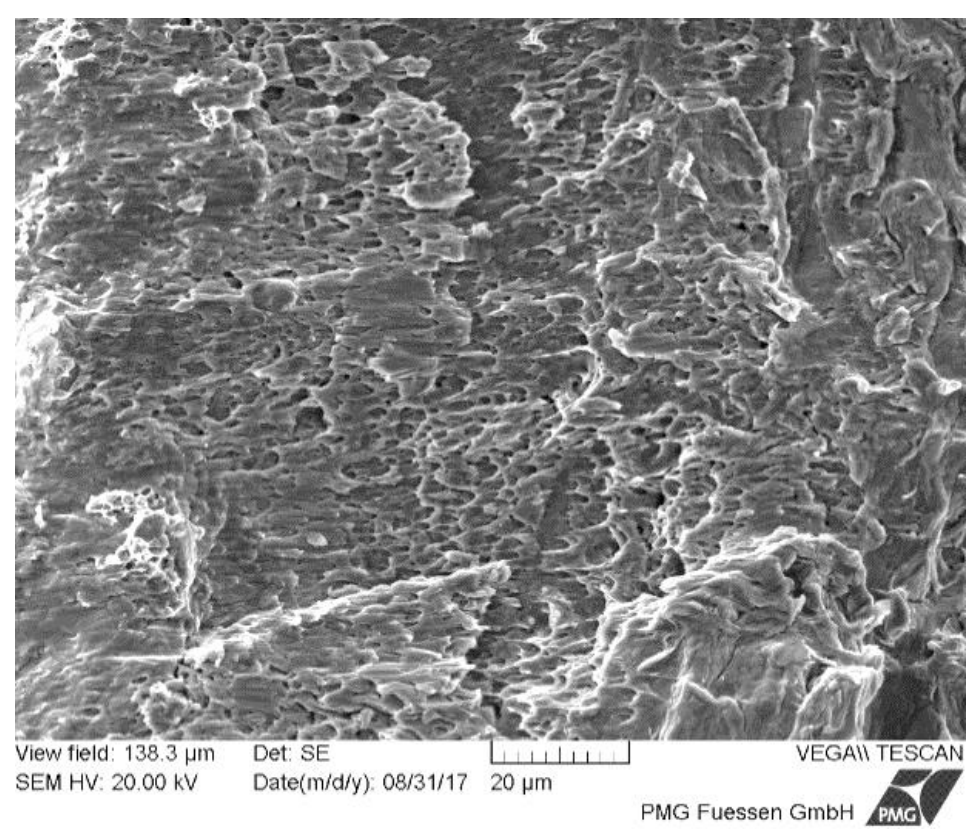

Figure 10: Fracture surface of the laser treated area.

Table 1: Microhardness HV0.5.

\begin{tabular}{|l|l|l|l|}
\hline Reference ring surface & Reference ring core & Laser treated surface & Laser treated core \\
\hline $60 \mathrm{HVO} .5$ & $60 \mathrm{HVO} .5$ & $118 \mathrm{HV} 0.5$ & $60 \mathrm{HV} 0.5$ \\
\hline
\end{tabular}

Table 2: Average values of three toroids.

\begin{tabular}{|l|l|l|l|l|}
\hline & Units & $\mathbf{1 0 0 ~ A / m}$ & $\mathbf{5 0 0} \mathbf{A} / \mathbf{m}$ & $\mathbf{1 0 0 0 ~ A / m ~}$ \\
\hline Magnetic force, $\mathbf{H}_{\mathbf{c}}$ & $\mathbf{A} / \mathbf{m}$ & 110 & 120 & 135 \\
\hline Magnetic saturation, $\mathbf{B}_{\max }$ & Tesla & 0.38 & 0.38 & 0.66 \\
\hline Permeability $\boldsymbol{\mu}$ & - & 637 & 629 & 540 \\
\hline Iron loss, $\mathbf{E}$ & $\mathbf{m J} / \mathbf{K g}$ & 13 & 18 & 36 \\
\hline
\end{tabular}

Table 3: Values of the reference toroid without laser treatment.

\begin{tabular}{|l|l|l|l|l|}
\hline & Units & $\mathbf{1 0 0 ~ A / m}$ & $\mathbf{5 0 0 ~ A / m}$ & $\mathbf{1 0 0 0 ~ A / m ~}$ \\
\hline Magnetic force, $\mathbf{H}_{\mathbf{c}}$ & $\mathbf{A} / \mathbf{m}$ & 64 & 72 & 92 \\
\hline Magnetic saturation, $\mathbf{B}_{\max }$ & Tesla & 0.30 & 0.32 & 0.61 \\
\hline Permeability $\boldsymbol{\mu}$ & - & 520 & 500 & 490 \\
\hline Iron loss, $\mathrm{E}$ & $\mathbf{m J} / \mathbf{K g}$ & 10 & 14 & 26 \\
\hline
\end{tabular}

perature in this area permits to obtain a local liquid for small parts, thin sections, or case depth work. phase " sintering".

\section{Hardness}

Hardness is a characteristic of a material, not a fundamental physical property. It is defined as the resistance to indentation, and it is determined by measuring the permanent depth of the indentation.

The Vickers hardness test method, also referred to as a microhardness test method, is mostly used

Often the prepared samples are mounted in a plastic medium to facilitate the preparation and testing. The indentations should be as large as possible to maximize the measurement resolution.

The Vickers hardness of the reference ring and of the laser treated ring was measured. The results of the micro hardness is summarized in the Table 1. The effect of densified surface after the laser treatment on the micro hardness is abso- 
lutely clear. The micro hardness of the surface is about $50 \%$ higher than the micro hardness of the reference ring.

\section{Determination of the magnetic properties}

The determination of the magnetic properties have been measured on three toroids in each state.

\section{Direct Magnet Field (DC) results}

The results of the magnetic properties in direct magnet field (DC) for the laser treated toroid are summarized in the Table 2 and for the reference toroid in the Table 3. The comparison of the values from the two tables for the iron loss shows clearly that the iron loss for the laser traded toroid is higher than the iron loss of the reference toroid. An increase of the applied lead to an augmentation of the iron loss and this from $13 \%$ at $500 \mathrm{~A} / \mathrm{m}$ to $38 \%$ at $1000 \mathrm{~A} / \mathrm{m}$. The permeability is higher for the laser traded toroid.

\section{Alternative Magnet Field (AC) results}

Core losses are defined as the power absorbed by a core under stated conditions of applied time varying magnetic field. Different approaches may be used to quantify the core losses when a magnetic material is exposed to alternating magnetic fields. One approach consists of determining the behavior of the material as a function of excitation parameters and material constants. The first component is related to the hysteresis portion of the core losses, which depends on the structure and composition of the material, the second component is related to the eddy-current losses while the last component refers to the excess losses or anomalous losses.

The core loss of the reference toroid and the laser treated toroids are represented in the Figure 11 for two different polarisation.

For these toroids at $>300 \mathrm{~Hz}$ the behavior by 0.5 and 1.0 Tesla is similar. The highest core losses are measured in laser treated rings and the lowest in reference material without laser treatment. At frequency $<200 \mathrm{HZ}$ the iron losses are under $50 \mathrm{~W} / \mathrm{kg}$. However at high frequency the core loss increases considerably.

\section{Conclusions}

The following conclusions have been drawn from this study:
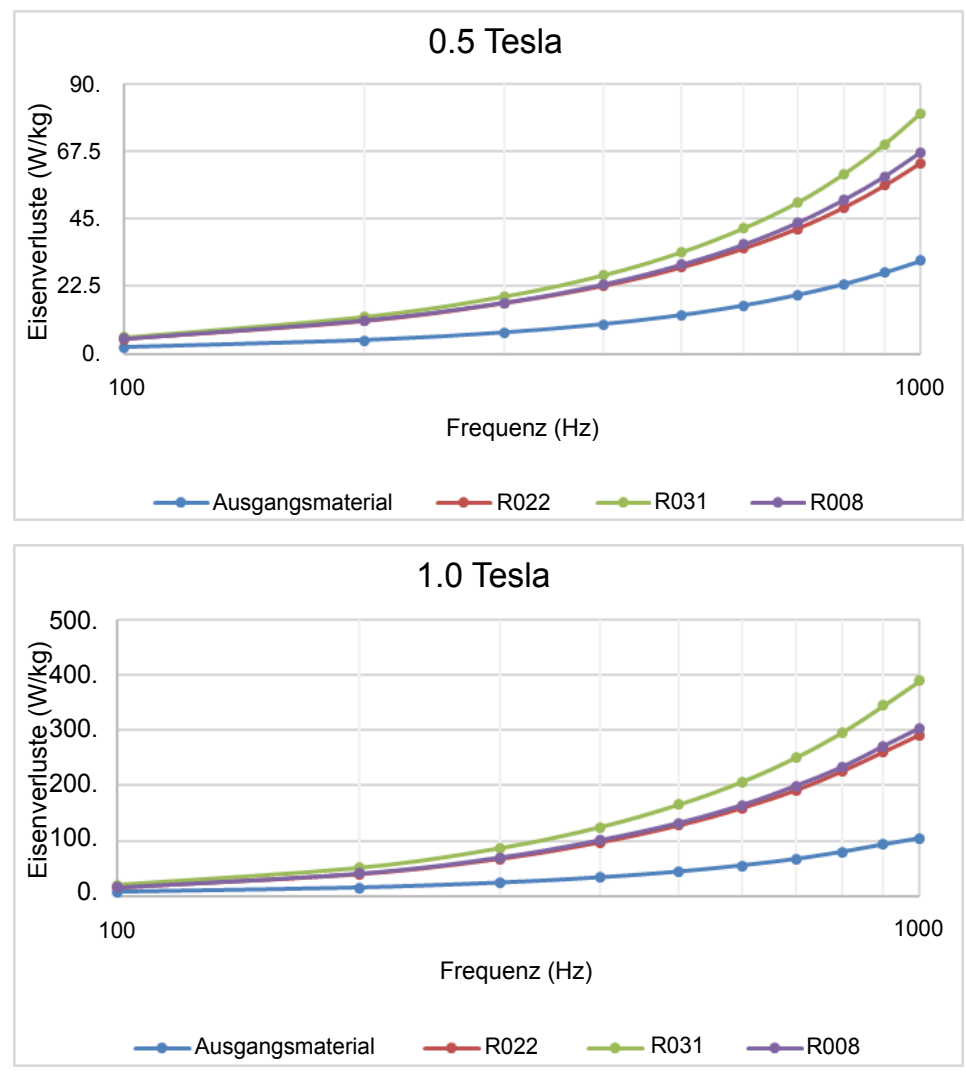

Figure 11: Core loss versus frequency at two different polarisation. 
- Laser treatment of a SMC material, that is not sintered at temperature $>1120^{\circ} \mathrm{C}$, lead to the formation of a thin area that is free of pores.

- With a laser treatment, it is possible to obtain a densification of the surface without a modification of the matrix.

- Due the presence of the densified surface, a modification of the magnetic properties is to consider, that depends on the thickness of the densified area.

- A decreased soft magnetic property and iron loss is released by the comparison to the reference ring.

- An increase of the hardness in the border of the surface is obtained.

In order to encourage the future development of the laser technology for SMC (Soft Magnetic Component), it is a requirement that the thickness of the densified area must be reduced to $<350 \mu \mathrm{m}$ to obtain lower core and iron loss than in this experimental results. This must be verified with new experience. Densified area deeper than this value $350 \mu \mathrm{m}$ lead certainly to a dramatic modification of the magnetic properties and first of all the core loss.

\section{References}

1. O Andersson, P Hofecke (2009) Advances in soft magnetic composites - materials and applications. PowderMetal 2009, Las Vegas, USA.

2. C Andersson (2018) Attachment methods for somaloy ${ }^{\circledR}$ in mechanical constructions. Lund University, Sweden.

3. Z Ye, M Lenberg, C Pompermaier (2012) A new generation of SMC materials with low core loss. PM2012 Yokohama, Japan.

4. L Pennander, AG Jack (2003) Soft magnetic iron powder materials ac properties and their application in electrical machines. EURO Powder Metallurgy.

5. LO Pennander, G Nord Höganäs $A B, K$ Maezawa, $M$ Saito (2005) Development of a soft magnetic composite core for a stirling cooler linear motor. LDIA, Japan.

6. NK Tolochko, YV Khlopkov, SE Mozzharov, MB Ignatiev, T Laoui (2000) Absorptance of powder materials suitable for laser sintering. Rapid Prototyping Journal 6: 155-161. 